Pak. j. sci. ind. res. Ser. A: phys. sci. 2019 62A(3) 202-214

\title{
Review
}

\section{A Review of Recent Progress in Efficiency-Power Correlations of Silicon Hetero-Junction Solar Cells}

\author{
Tahir Iqbal*, Amna Azam, Aqsa Tehseen and Almas Bashir \\ Department of Physics, University of Gujrat, Hafiz Hayat Campus, Gujrat-50700, Pakistan
}

(received November 2, 2018; revised February 23, 2019; accepted February 26, 2019)

\begin{abstract}
Solar technology is widely used to generate the electricity. It is fundamental p-n junction that supplies the emf whenever sunlight falls on it. A lot of efforts have been incremented by inserting the impurity level in the semiconductor band gap to enhance the efficiency of the solar cells. Copper zinc tin sulphide $\left(\mathrm{Cu}_{2} \mathrm{ZnSnS}_{4}\right)$ devices are the highly stable and efficient part for the most fundamental of many solar cells. Cadmium (Cd) doping is carried out to enhance the efficiency of CZTS. Cadmium sulphide $(\mathrm{CdS})$ consists of band gap that is $2.4 \mathrm{eV}$. Ternary organic solar cells attract the researchers interest level due to the best absorbing capacity that is much easier to handle but the exclusive difficulty in dealing with its morphology. Thin film solar cells have greater coefficient of absorption because of its high functioning and have band gap value in the range between 1.5 and $1.0 \mathrm{eV}$. Solar cells consists of chalcopyrite on a polyimide film that demonstrates the largest cell efficiency approximately $18.7 \%$.
\end{abstract}

Keywords: copper zinc tin sulphide (CZTS), silicon crystalline, titanium dioxide $\left(\mathrm{TiO}_{2}\right)$, nano-fluids, polyimide film

\section{Introduction}

Photovoltaic arrangement is a technique that produces electricity through the transfer of solar energy into electricity with the semiconductor assistance. They are classified into three main categories: Semiconductors, Conductors and Insulators. PV cells are constructed with semiconductor materials, insulator and the addition of impurity (such that boron and phosphorus etc.) that enhance the conductance of these cells. When silicon doped with phosphorus then it is ' $n$ ' type. When silicon is doped with boron it is ' $p$ ' type. Overall p-n junction is constructed and it is electrically neutral. When ' $n$ ' type is affiliated with ' $p$ ' type, electrons are considered as the diode electrons and due to the diffusion of electrons electric field is built up in opposite direction. For this purpose some of the emf is required to remove the potential barriers. Solar cell consists of various cover glass grid. The coating that blocks the reflection and losses and the contact grid that is used to collect the electrons from the ' $n$ ' type. The ' $p$ ' type thickness is 100-350 $\mu \mathrm{m}$ and the ' $\mathrm{n}$ ' type thickness is $2 \mu \mathrm{m}$ and the top grid is ' $n$ ' type and the bottom it is ' $p$ ' type that is opaque black metal and considered as the positive and negative depot. Solar cells basically acquire their energy from phonons (Zekry, 2004) (Fig. 1). These cells are *Author for correspondence; E-mail: tiqba102@qub.ac.uk appliances when sunlight falls on it that ejects electric charges from the semiconductor and these charges move freely in the wire and then transfer to the electrical load for example like lighting bulb. The procedure of generating the voltages and the production of currents is known as photovoltaic effect (Hu and Chen, 2007). The sunlight is fuel for the solar cells that is abundant and free of cost in the atmosphere. On the surface of earth, the sunlight intensity is almost 1000 watts $/ \mathrm{m}^{2}$. It is the fundamental factor that utilizes in the terrestrial applications and they are economically alternative sources (Rand et al., 2007). Due to rise of the economic pressure conventional sources like fossil fuels are limited and they are very expensive. The basic fact is to reduce the price of electricity for the utilization of the solar technology. From the economic point of view solar cell option is increased due to its attractive attributes that enhance the cell efficiencies and the reduction of prize of the generating cells (Liu et al., 2008).

When sunlight inserts in the semiconductor and generates positive and negative charges and they are free to move, and these particles cross the energy barrier that acts as the depletion layer that allowed to pass one type of charges, and block the other types of charges. These positive charges assemble on the upper adjoin and the negative charges on the lower adjoin. Due to these 
collections of charges electric current is created that flow via wires to the gadget (Green et al., 2011). Universal utilization of the cells for the generation of the power is photovoltaic effect that is acknowledged in 1839 and the first description about the silicon solar cells is in 1954 and further utilization in the solar cells is launched in the spacecraft (Gilles and Sariciftci, 2005).

Utilizing silicon is on the integrated circuits that is comprehending and it is the best alternative in the solar cells and other addition is being developed in these types of technologies. Manufacturing of single crystal cells due to polycrystalline cells are produced that demands the broad ignition. The deliberate crystal development slice up is economic for the enhancement of energy generation process and it is the cost effective (Siegel et al., 2010). In the semiconductors utilization of the mirrors and the focusing lenses are very cost effective per unit area and they are affordable. The utilization of the "concentrator" the arrangement allows sunrays to concentrate onto comparatively diminish semiconductor cells (Lungenschmied et al., 2007). Cells are manufactured for the one wavelength that is frugal to collapse the spectrum that is minimized the spectral constituents and conduct various constituents on cells (Kondo et al., 2008; Yang et al., 1997). Sunlight accessibility and the energy requirement oscillates. Solar cells are supplying fundamental energy storage within the cell due to electrolysis that are called photoelectrochemical cells and these cells are effective (Green et al., 2011).

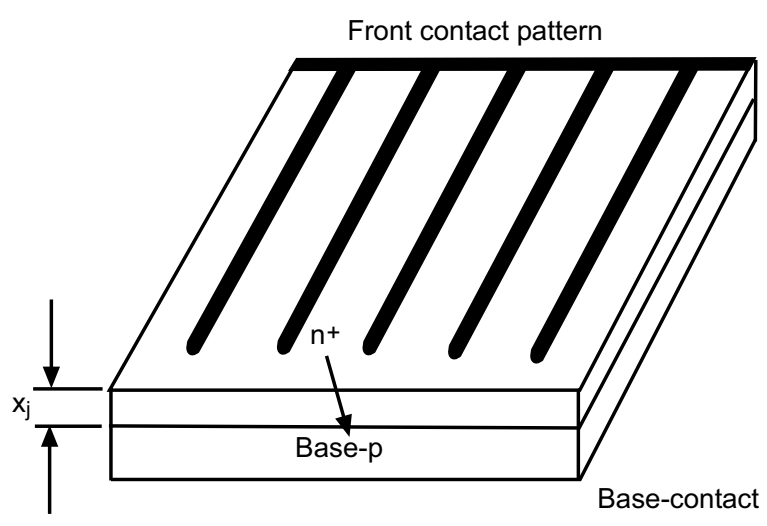

Fig. 1. Basic construction of solar cells (Zekry, 2004).
Silicon cells are constructed on the wafers cut with saw from the prominent single-crystal metal bar. From different kinds of single-crystal cell to the gallium arsenide compound semiconductor is utilized in many experiments due to higher efficiency and its working capability at higher temperatures (Ahlswede et al., 2007). Concentrator and non-concentrator cell systems are the different types of systems. Concentrator manufactures with gallium arsenide and silicon (Wu et al., 2001). Concentrator cells resist the high temperatures due to the comparatively high cell currents that have low resistive deprivations. Due to the illumination with comparatively long wavelength and higher efficiency when the light falls on the plate "thermophotovoltaic" (Lenert et al., 2014).

Majority cells utilize the junctions that comprise different types of impurities within the semiconductor that have dissimilar electrical attributes with two adjacent areas like silicon. Schottky-barrier cell is the alternative structure in which one of the regions of $p-n$ junction cell of semiconductor is replaced by moderately crystalline metal film (Rand et al., 2007).

Most prominent cell manufactured design is that in which semiconductor and metal addition of very dilute insulating realm that manufactures the metal insulator semiconductor (MIS) (Rand et al., 2007). Enhancement of the electromagnetic field on the surface plasmon in semiconductor solar cell surface that is most anticipating instrument for the enhancement of the optical absorption due to the excitation of the surface plasmon (Akimov et al., 2009). The fundamental purpose of the photovoltaics for the construction of the solar cells is to reduce the yield monetary value and to manage the configuration with different kinds of power production. The main purpose is to decrease the power production prices less than $\$ 1 /$ watt (Ostrikov et al., 2008). One method is to reduce the cast in dilute film manufacturing. Absorbing layer thickness is only in the range of micrometer. Various kinds of technologies are used for the manufacturing of the solar cells and they are magnetron sputtering, electron beam evaporation, plasma-enhanced chemical vapor deposition and hot filament-assisted deposition. These techniques are enhanced due to the utilization of the momentum nanostructure that enhance the efficiency of the solar cells (Gordillo-Vazquez et al., 2007; Kurokawa et al., 2007). 
The best method is to enhance the efficiency of the solar cells and energy conversion that utilizes the electromagnetic field on the metal airfoil. Titanium dioxide $\left(\mathrm{TiO}_{2}\right)$ materials utilizes in the wide range in the applications like in solar cells, catalysts etc. (Liao et al., 2018; Kondo et al., 2008). Titanium dioxide $\left(\mathrm{TiO}_{2}\right)$ prominent thermal attributes are mechanical, photocatalytic and electrical. Band gap of $\mathrm{TiO}_{2}$ in anatase phase is almost $3.2 \mathrm{eV}$. It is stable functioning, affordable, non-poisonous. $\mathrm{TiO}_{2}$ is the best photocatalyst and recognized in the anatase phase (Rajeshwar et al., 2008). For the purpose of the best application $\mathrm{TiO}_{2} \mathrm{NT}$ arrays suggest further modification with energy level in the narrow band semiconductors. $\mathrm{TiO}_{2}$ is altered by $\mathrm{CeO}_{2}$ and that is feasible in the gas sensors field and the photocatalysis field. Band gap of $\mathrm{CeO}_{2}$ is $2.92 \mathrm{eV}$. (Liao et al., 2018). Gretel cells gained a lot of concern in between all dye-sensitized solar cells (DSSCs). DSSCs efficiencies is enhanced by almost $6 \%$ after that in 1991. Its efficiency value range is $7.1 \%$ (Venkatraman et al., 2018). Perovskite solar cells devices anticipated for the commercial diligence because they are more affordable due to earth abounding materials that shows all the qualities of the photovoltaics cells (Christians et al., 2015).

Optical increment on the thin-film is increased the enhancement of the amorphous silicon solar cells and its thickness is $0.75 \mu \mathrm{m}$ (Deckman et al., 1983). Conjugate polymer utilizes the technique of the organic solar cells and they are the fullerene blends. Its efficiency is almost greater than the $4 \%$. It is fundamental technique that is exclusive and fundamental $\mathrm{Nd}$ : yttrium aluminum garnet (YAG) laser that contains the following attributes like engraving, affordable of simple structure and providing the interface for the charge transfer (Dennler et al., 2005). Plastic solar cells generate power and have efficiency almost $5 \%$. It is the alternate energy resource that demonstrate the yield growth almost $30 \%$ annually (Green, 2009).

In 1941 the first silicon solar cells were depicted with $1 \%$ energy transition efficiency that corresponds to $25 \%$ efficiency due to the standardized measurement from the past work and later $57 \%$ that sustained the enhancement as the consequences that are collected in 1983. (Temple et al., 2009). Solar cells consist of the inarguable fundamental fact towards the sustainable energy that is sufficient for the world requirement and a lot of new technologies are raising to meet the new objectives of the world energy demand. World energy demand is increasing due to the world population and other energy resources are depleting and energy demand is increasing gradually with the passage of time and these resources are expensive. So, alternate energy resource is desired for this reason and the sun is the best alternate of energy. Utilization of energy is $40 \%$ of sun. Sunlight that falls on the earth is not visible and lie in the region of ultraviolet of silicon spectrum. The conventional photovoltaic is based on the silicon in which half of it is unused. Fossil fuels are not healthy for the environment and they are finite energy resources so basic need is availability of the renewable energy resources that are more affordable and more efficient. Scientists are working to replace the silicon with plastic or organic polymers that are more elastic and affordable. Organic polymer solar cells are less expensive than silicon because their manufacturing cost is less than silicon and they are coated in the same way on the airfoil. The same technique is utilized in the spray paints that is more easily manufactured like in newspaper printing off. Solar energy is free and harmless and our goal is to produce the material device that is both efficient and flexible (Sharma et al., 2015). The solar cell energy started in 1876 by William Grylls Adams with his student Richard Day. They discovered when they came to know that electricity is created whenever light falls on the selenium. After sometime the Werner von Siemens discovered that selenium cells are not effective but only proved that without heating effect electricity can also be produced because of light. Silicon solar cell are discovered by Calvin Fuller, Daryl Chapin and Gerald Pearson in 1953. The first commercially available solar cell is disclosed in 1956 and utilized in radios and toys and after that lower cost solar cells are discovered in 1970 after that in 1990 further modification occurs in the solar cells. The solar cell is not novelty for the researchers that are utilizing for the enhancement in the larger commercial level that reduces the dependence on the fossil fuels so that environment become clean. The solar energy will become the best contributor of the energy (Ansari et al., 2018; Sharma et al., 2015).

Global energy demand is raising almost $70 \%$ due to utilization of the fossil fuels and energy demand is encountered almost $80 \%$ because our sources are depleted. In 2002 fossil fuels for oil were predicted that these resources will be depleted for the next 40 years, for example the natural gas for 60 years and for the 
coals 200 years. On the other hand environmental conditions like global warming and the drastic conditions that effects the energy demands. The fossils fuels that are depleting to compete the energy requirement so, we need environment sustainable resources. The renewable energy technology is applied in the following techniques for example hydropower, solar cells, biomass-derived liquid fuels like solar cells that are converting $0.1 \%$ of the earth surface with only $10 \%$ of the efficiency that satisfies the condition only for the present use. Solar cells contain energy from the sun and substitute into electricity. Researchers practically transferred sun rays into electric energy for the first time in 1954 at the Bell Telephone Laboratories that accomplished about 6\% efficiency by the utilization of $\mathrm{p}-\mathrm{n}$ junction solar cell due to the establishment of the space platform. Photovoltaic cells contain silicon that rapidly turned into power source as the alternative for the utilization of the satellites. In 1954 a lot of papers have been written regarding to the efficiency of the solar cells but only Chapin, Fuller and Pearson are recognized by their outstanding work. The intervention of the new work is done by Pfann and van Roosbroeck due to addition of analytical formulas that is optimizing the load. The efficiency of energy gap was studied by Prince after that Loferski has arrived to anticipate the dependence on the energy gap. Mostly discussions in all the papers are totally based upon the properties of the solar cells that is related to the empirical values of the constants. This anticipation is considered as the theoretical limits. After that the consequences were updated in $\mathrm{n} \mathrm{p} \mathrm{Si}$ wafer reference spectrum. The assumption is that the dilute layer of $\mathrm{n}$ silicon is developed due to the diffusion process (Ng et al., 2018; Krebs, 2009). Energy utilizing has become the essential part in life for the last ten years because of the sudden rise of the energy requirement, furthermore the problems that are from the utilization of conventional energy is the environment problems like global climate change and global warming that drive us to substitute the resources. World Health Organization gives the statistics report according to that 160,000 people died annually due to global warming and the other environment effects and this rate is raised to double as estimated by the end of 2020. Climate change causes troubles like disasters as flood tide, shortage of rainfall and notable environment changes in the temperatures. Furthermore, these troubles create dangerous diseases that are fundamental in the society like diarrhoea and malaria etc. In 2003, 20,000 people died and $\$ 10$ billion losses in agricultural area when disasters were reported in European countries. In present era, $80 \%$ conventional energy sources are the part of energy utilization. In the mid of $20^{\text {th }}$ century, recommended need of our society is the replacement of these resources that put off with the advent of nuclear energy that represents 20 times more from fusils fuels (Zhai and Alexandrova, 2017).

Nuclear based solar cells development. There are some restrictions in nuclear energy. To illustrate fusion process in which it is disclosed to uranium and thorium resources that are considered as fusil fuels. Moreover, nuclear power plant is only on the larger level for the power production due to its production aspects but only for smaller level like cooking and heating renewable energy resources are the best alternative. It is the best choice of human survival on this earth and alternate of fossil fuels that almost utilized in 2006. According to world energy demand the renewable energy resources has a lot of advantages but impart energy almost $1.5 \%$ and it will be raised upto1.8\% in future almost in 2030 . The most fundamental use of energy is being in the industrial processes that energy demand raised up to more than $50 \%$ of total worldwide energy fraction. Industrial energy is transfer and used in 4 areas for example in construction work, agriculture sector, mining sector and manufacturing sector (Mekhilef et al., 2011; Ni et al., 2007).

This review is mostly discussion of all types of solar cells and their techniques that gradually changes and development occur in the phases of solar cells types and how solar cell developed from basic silicon solar cell to different advance solar cell types and how its efficiency is increased and cost is reduced and it becomes more flexible and portable. The idea behind is that every portable device that we use is mostly require to be charged periodically so that we need to become more patient and wait for charge of these devices. Just like imagine if we slip our mobile into our pocket and our mobile become charged just because of our fabrics transfer charges and convert into electricity because sunlight is much cheaper and environment friendly and creates no more harm. Further, this discussion shows that how we can improve this photovoltaic technology. For this purpose this review has discussed all types of solar cells and how its efficiency is improved by different 
processes. Flow chart of solar cell types is mentioned in Fig. 2.

CZTS based solar cells. Copper zinc tin sulphide $\left(\mathrm{Cu}_{2}\right.$ $\mathrm{ZnSnS}_{4}$ ) based devices become highly stable and efficient that is fundamental of many solar cells (Zhai and

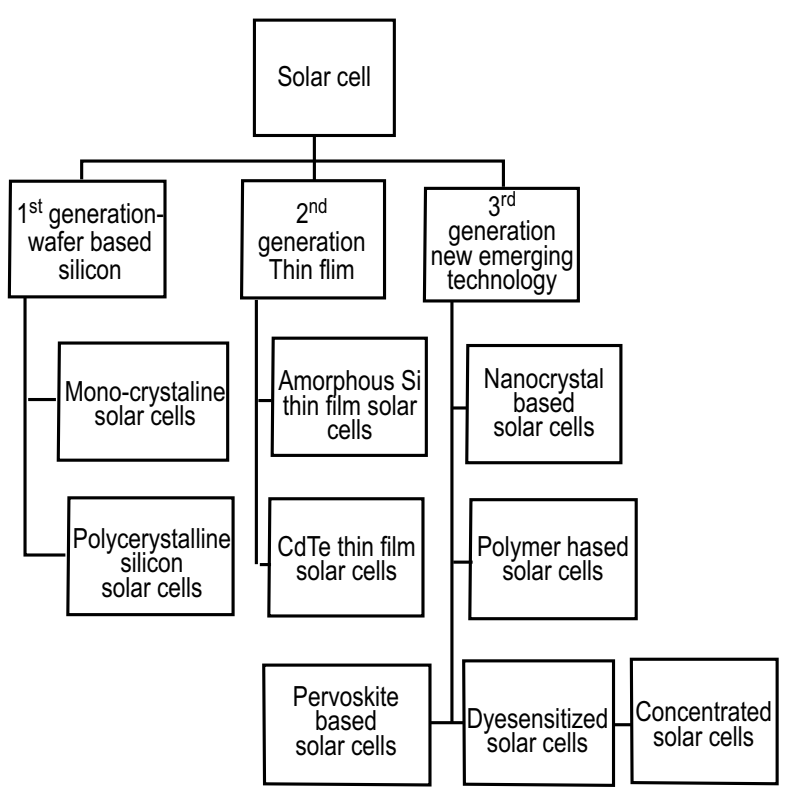

Fig. 2. Flow chart of solar cell types (Sharma et al., 2015).

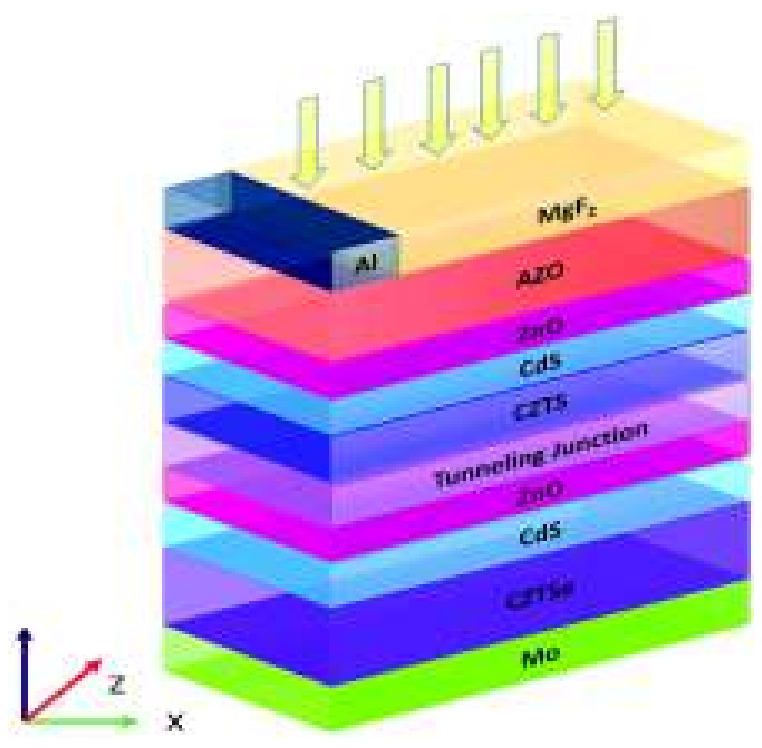

Fig. 3. Basic structure $\mathrm{Cu}_{2} \mathrm{ZnSnS}_{4}$. (Saha and Alam, 2017).
Alexandrova, 2017). A lot of devices are made from this method. CZTS is kesterite structure the absorber layer is the best for solar cells that is suitable for the photovoltaic and usually band gap is nearly $1.5 \mathrm{eV}$ with larger efficiency that is $42 \%$. In Fig. 3 basic structure of CZTS is illustrated (Ravindiran and Praveenkumar, 2018).

A lot of work has been published on copper zinc tin sulfide (CZTS) that is semiconductor compound usually appears as the thin film that is basis for the preparation of photovoltaic. Due to this reason it has the best absorption coefficient and good drawing compound. $\mathrm{CZTS}\left(\mathrm{Cu}_{2} \mathrm{ZnSnS}_{4}\right)$ complex has easily available elements. Its manufacturing is very easy and they are nontoxic, environmental-friendly, affordable and the best functioning. Actually, addition of kesterite in solar cells enhance the efficiency of solar cells and band gap is improved for the functioning of kesterite. CZTS compound is that compound whose band gap is minimized for any photovoltaic which is approximately 1.4-1.5 $\mathrm{eV}$ and additional high absorption coefficient that is utilized as the absorber layer in the visible region $>104 / \mathrm{cm}$. Cadmium (Cd) doping is executed to enhance the efficiency of CZTS. Cadmium sulphide (CdS) consists of band gap that is $2.4 \mathrm{eV}$ and it is absorber layer on which a lot of research work is done for the improvement on the band gap engineering. Mostly research papers are based on the structures and function of the solar cells ( $\mathrm{Ng}$ et al., 2018; Ravindiran and Praveenkumar, 2018; Green et al., 2011).

Electron beam evaporation technique CZTS based solar cells. Electron beam evaporation is vapor deposition technique in which electron beam strikes at anode in vacuum environment to evaporate the substance from anode. The substance evaporates and deposits as thin film and that technique is used to produce the thin film devices. Thickness depends upon the substance size and vacuum type. Utilization of this method is to construct the photovoltaic system with thin layers $\mathrm{ZnO}$ : $\mathrm{Al} / \mathrm{CdS}$ and $\mathrm{CZTS} / \mathrm{Mo} / \mathrm{SLG}$ by providing the suitable conditions whose efficiency is obtained $0.67 \%$. In order to increase the efficiency from this method later work was done by Hironori et al. (1997). They utilized $\mathrm{Cu}$, $\mathrm{Sn}$ (or $\mathrm{SnS}_{2}$ ), and $\mathrm{ZnS}$ and the evaporation process occur and further addition of soda lime glass (SLG) enhances the efficiency up to $5.43 \%$ (Ravindiran and Praveenkumar, 2018). 
Magnetron-sputtering technique. Magnetron-sputtering method utilizes the magnetic field for the deposition on the film's substrate. From this method the CZTS are established whose efficiency is enhanced by $3.69 \%$ (Ravindiran and Praveenkumar, 2018).

Ternary organic solar cells. Ternary organic solar cells contain all the researcher interest level to enhance the simplicity from the exclusive junction appliance and its working is improved due to its absorbing capacity but exclusive difficulty in dealing with its morphology. All the development demonstrates in this field is organic solar cells (OSCs) that contributes and increase its efficiency up to $10 \%$ but multi junction solar cells have more efficiency as compared to single junction but exclusive difficulty is in manufacturing process but its cost is elevated. It is better to use the single junction device because of its simplicity but decelerate its development due to its restriction and dealing with ternary blend and its morphology due to lack of any efficient methods of dealing with its morphology. Its significant approach is to deal with ternary a material selection rule that is used to speed up the progress in this field. Non-fullerene organic photovoltaic (OPVs) speed up its progress when PTFB-O polymer is used in this process. Illustration of various properties of polymer is shown by UV-visible spectra in aqueous solvent on several temperatures (Jiang et al., 2018; Aberle, 2001). Figure 4 represents working principle of ternary organic solar cells in (a) charges are transmitting, (b) energy transmits principles, (c) autonomous holes transfer mechanism and (d) arrows show charge carriers transmission.

Polymer based solar cells. Polymer is dismissed in solvent with low collection at the high temperature that equates the absorption of blue shift at low temperature. Photovoltaic are clean, regenerate and standard replacement of energy. In PV industry silicon solar cells are dominating. It will be suitable if we discover other photovoltaic materials that contains certain qualities like elastic, affordable, coherent and suitable. Polymer solar cell (PSCs) is bulk hetero junction (BHJ) whose qualities are suitable for simple fabrication is the best alternative source of energy (Aberle, 2000).

Crystalline based solar cells. Crystalline solar cells efficiency is about $20 \%$ almost in 1980 due to the advancement in led airfoils that have higher efficiency in the present mode shift to the dilute wafers in industry. The silicon crystalline is very important due to its commercial usage and passivation of surfaces methods like laboratory and industrial methods that are discovered almost since 1970. From these methods manufacturing of $\mathrm{p}$ and $\mathrm{n}$ junction that transform to the plasma silicon nitride. Crystalline silicon has greater recombination
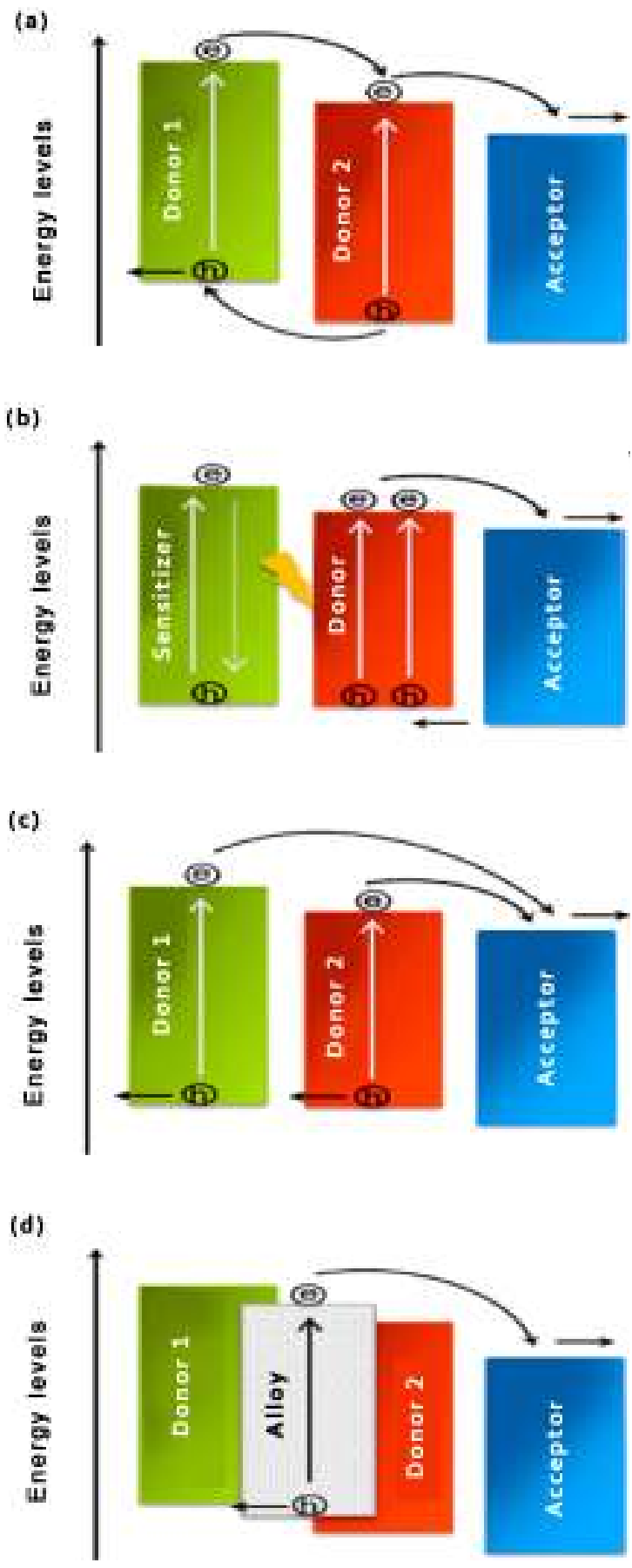

Fig. 4. Basic principle of ternary organic solar cells (Fu et al., 2018). 
losses due to being indirect semiconductor and have band gap due to its defect level these defects are within the volume. There are two types of defects intrinsic and extrinsic. Due to float zone method that is silicon growth method and these defects can be removed to very small level defects that are density of extrinsic bulk defects. Silicon is more complex due to involution on the surface on non-silicon atoms. On these surfaces atoms and its symmetry is disturbed due to these defects and dangling bonds. These defects are transformed into extrinsic defects. For the control of these defects the passivation of surfaces method is used (Li et al., 2006).

Silicon crystalline based solar cells. Solar cell functioning is essentially raised the internal carriers recombine rate. The carrier concentration rate is raised due to the rise in temperature and their functioning falls with the raising in the photovoltaic conversion process and control by the temperature that plays a main role. Because to these parameters its efficiency and output power linearly depends on its functioning temperature (Aberle, 2001).

Titanium dioxide $\left(\mathrm{TiO}_{2}\right)$ nano-sized photo-catalytic water-splitting technique. Solar energy conversion process has very low efficiency and it is not economically good. It is affordable and suitable for the environment that is solar hydrogen generation method. Titanium dioxide $\left(\mathrm{TiO}_{2}\right)$ nano-sized photocatalytic water-splitting technology is concerned for the generation of solar hydrogen. In this process main trouble is the poor activation from the visible light of titanium dioxide $\left(\mathrm{TiO}_{2}\right)$ (Fig. 5). Other draw backs are the instant recombination and the backward reactions of photo-generated electron/hole. Due to these shortcomings researchers are working on its remedy methods. Some researchers used the alternates and improved the carbonate salts

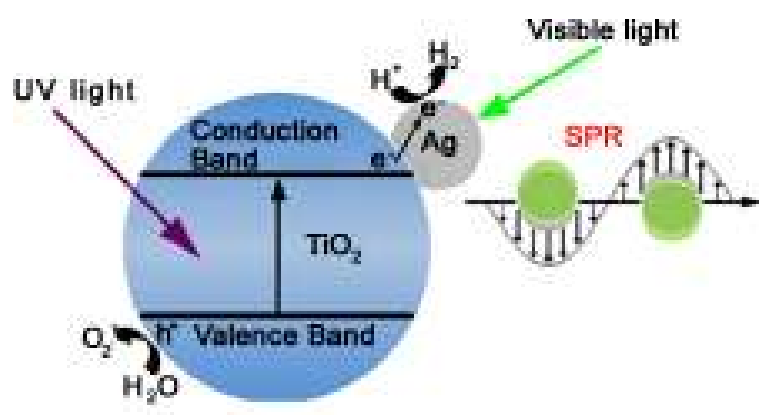

Fig. 5. Mechanism of photocatalytic water splitting (Wu et al., 2013). with sacrificial reagents that forbids the instant recombination and backward reactions. Some researchers worked on the modification of the titanium dioxide $\left(\mathrm{TiO}_{2}\right)$ that enhanced the photo-catalysis due to different methods like doping. The modification of titanium dioxide $\left(\mathrm{TiO}_{2}\right)$ occurs due to metals doping (Thomas et al., 2014; Ni et al., 2007; Li et al., 2006).

Titanium dioxide $\left(\mathrm{TiO}_{2}\right)$ based solar cells. Titanium dioxide $\left(\mathrm{TiO}_{2}\right)$ based solar cells consists of techniques like loading, metal ion doping and composite semiconductor etc. The technologies are implemented to titanium dioxide $\left(\mathrm{TiO}_{2}\right)$ for the development of photo-catalytic hydrogen generation. Different types of methods are utilized to cover the energizing spectrum that converts to visible spectrum. From the research point of view we came to know different methods like dye sensitization, ion doping and metal ion implantation that are best methods for the generation of photo-catalytic hydrogen production.

Hydrogen is conceived as the best fuel for the future. Life cycle of hydrogen fuel production is renewable due to its connection with renewable energy origins. Two major energy origins are wind and solar that are the most significant origins for the hydrogen energy. The renewable energy is assisting $5 \%$ for the hydrogen generation due to the water and $95 \%$ energy is obtained from the fossils fuels (Ni et al., 2007; Richards, 2004).

Photovoltaic water electrolysis technology. Renewable hydrogen generation is not boastful because it is expensive. The advancement in technology accommodates the photovoltaic water electrolysis which is less expensive, manageable due to the small band gap that creates the serious environment effects on the atmosphere. Titanium dioxide $\left(\mathrm{TiO}_{2}\right)$ is substituting in the photocatalytic water-splitting. The recent work was reported by Fujishima and Honda (1972) on titanium dioxide $\left(\mathrm{TiO}_{2}\right)$ for the photo-electrochemical hydrogen generation. The work on the semiconductor photocatalytic water and air purification are the fundamental process that creates the hydrogen production and photo production of holes or electron pairs. There are different methods for the utilization of these electrons or hole pairs. The reduction of $\mathrm{CB}$ electrons are essential for the reduction of protons in the hydrogen molecules and CB level are more negative that initiates the hydrogen generation (Mahian et al., 2013). 
Overview on titanium dioxide $\left(\mathrm{TiO}_{2}\right)$ based solar cells. In an overview (Sakhtivel et al., 2017) in which they wrote on the hydrogen production due to semiconductor particulate matter systems with different types of photocatalysts for hydrogen generations. Their potentials are discussed in this overview like titanium dioxide $\left(\mathrm{TiO}_{2}\right)$, silicon carbide $(\mathrm{SiC})$ and cadmium sulphide (CdS). The energy transfer efficiency demonstrated in this field is the organic solar cells (OSCs) that increases its efficiency up to $10 \%$. Multi junction solar cells have more efficiency as compared to the single junction but exclusive difficulty in its manufacturing that elevated its cost (Jiang et al., 2018; Aberle, 2001).

Photocatalytic water-splitting from solar to hydrogen is not prominent. When $\mathrm{CB}$ electrons immediately falls on the VB holes and combination occurs that relinquish the energy as the waste heat. When water decomposes into hydrogen and oxygen, the energy is enhanced by this process. The recombination of both hydrogen and oxygen takes place and conversion occurs so that the backward reaction can easily start. Titanium dioxide $\left(\mathrm{TiO}_{2}\right)$ band gap is $3.2 \mathrm{eV}$ because the ultraviolet light utilizes for the generation of hydrogen (Pysch et al., 2007; Richards, 2004).

UV light contributes approximately $4 \%$ of solar energy and instead of visible sun light that constitute almost $50 \%$ that restricts the solar photo-catalytic hydrogen generation and its efficiency. After resolving all the problems that are mentioned above hydrogen production will be affordable, feasible and a lot of efforts have been made that enhance the photo-catalytic activity and improvement in the visible light reaction (Tanabe, 2009).

Researchers indicate that nanoparticles like $\mathrm{Ag}$ and $\mathrm{Au}$ are noble metals that enhance the attributes of the $\mathrm{TiO}_{2}$ at the Plasmon resonance surface that is SPR effect in the visible region is considered. When the light falls on the free electron of metal surface they jointly oscillate and SPR effect produces the light energy in the meantime (Wu et al., 2013).

Nano-fluids based solar cells. Solar power devices withstands the utilization of the nano fluids that are solved and these fluids are the heat conversion oil water and ethylene glycol that have significant act in the industrial processes like electricity production, igniting or temperature reduction processes and other chemical processes. It is essential in the thermic engineering gadgets and these kinds of fluids comparatively deplete the thermic conduction and execution cannot be carried out in the larger heat conversion. In order to defeat these problems for the enhancement of thermic conduction by the utilization of the fluids with appropriate ultra-fine solid substances. Nano fluids are typical suspension of the conventional that demonstrates the fluid whose nano-size particles are mostly in the range of 1-100 nm. In 1995, choir invented the first who used this term "Nano-fluid". Nano-fluids equated the suspensions generally in size with the millimeter and the micro that demonstrate the best constancy, rheology attributes and substantially more prominent thermal conductance (Mahian et al., 2013).

Researchers inquired to improve the thermic devices so that the heat conversion effects enhance the nano fluids in both experimental and theoretical bases. Many research workers are utilizing the diversity of the formulation methods. Their attributes are utilizing in various processes that are affecting the attributes of thermo-physical calculations of the nano-fluids like density, viscosity thermal conductivity and the specific heat capacity. Research workers are working on the effects of nano-fluids on the aerodynamic and heat conversion of various organizations that summarize its nano-fluids effects. The improvement of thermic effects on the nano-fluids that is fundamental and tremendous invention due to heat conversion that is important to a lot of industrial areas that consists of conveyance, power propagation, micro fabricating, metallurgical and chemical areas, thermic method of cancer intervention like igniting, chilling, respiration and air-cooling. Nano fluids contributes the significant role in the generation of nano materials the organizing building complex fluids for the cleansing oils because of their awesome diffusion and wetting. Kleinstreuer proposed that the nano fluid stream is contributing as the Nano-drug (Mahian et al., 2013).

Optical filters can enhance the solar transfer efficiency in the thermal $(\mathrm{PV} / \mathrm{T})$ collectors and addition of the nano fluids $\mathrm{Ag}-\mathrm{SiO}_{2}$ with 0.026 wt.\% that enhanced almost $30 \%$ efficiencies in comparison with fluid filter base. From Fig. 6 it is graphically represented (Hjerrild et al., 2016).

CZTSSe thin film solar cells. Thin film solar cells consists of the dilute -film - chalcogenide - kesterite $\mathrm{Cu}_{2} \mathrm{ZnSnS}_{4}$ and its abbreviation (CZTSSe) predicts the following prospects for the future that provides $\mathrm{Zn}$, $\mathrm{Sn}, \mathrm{S}_{2}$ and greater coefficient of absorption because of 


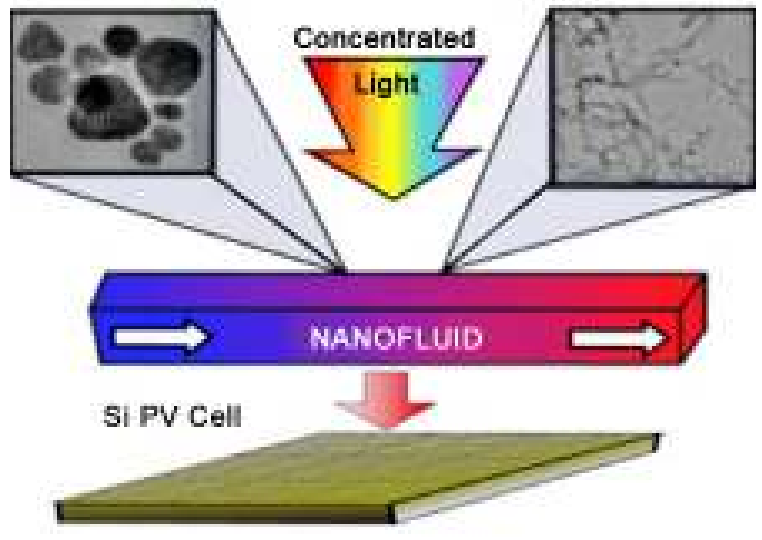

Fig. 6. Mechanism of optical filters (Hjerrild et al., 2016).

these aspects the high functioning and band gap value in between 1.5 and $1.0 \mathrm{eV}$. By utilization of the CZTSSe that is equally absorbent on the stratum in the photovoltaic diligences on the higher scale that elaborate the establishment of the response (Thomas et al., 2014).

In the recent demonstration of decomposition reaction the existence of $\mathrm{Sn}$ that $(\mathrm{S}, \mathrm{Se})$ throughout the larger temperature formulation paces that are requisite to prohibit the decomposition reaction that amends the efficiency of 0.02 to $6.1 \%$. Solar cell efficiency consists of decomposition reaction that is worldwide. Assimilation develop due to higher temperature vaporization and samples are developed due to lower temperature precursor. Assembly accompanied in $\mathrm{S}$ or Se substances are equated due to annealing in tube oven that clarify the consequences (Upama et al., 2018). CZTSSe solar cell in addition with Ge buffer layer indicates the efficiency of almost $2.00 \%$ that is improved as compared to without Ge buffer airfoil whose efficiencies are almost $200 \%$ (Li et al., 2017) (Fig. 7).

CIGS based solar cells. Solar cells are fundamental and consists the chalcopyrite. It is copper indium gallium selenide solar cell and its chemical formula is $\mathrm{Cu}$ (In, Ga) $\mathrm{Se}_{2}$ and abbreviation is (CIGS). The absorbent layers demonstrate the greater potential for the affordable solar power production that yields the polycrystalline Si wafer-based cells with corresponding efficiencies that covers the foundation which reduces the cost (Fig. 8). The efficiency of inflexible glass substratum is almost $20.3 \%$. For the development of modules that yields in the advance areas on the elastic substratum that is arrived at modern areas of diligences.
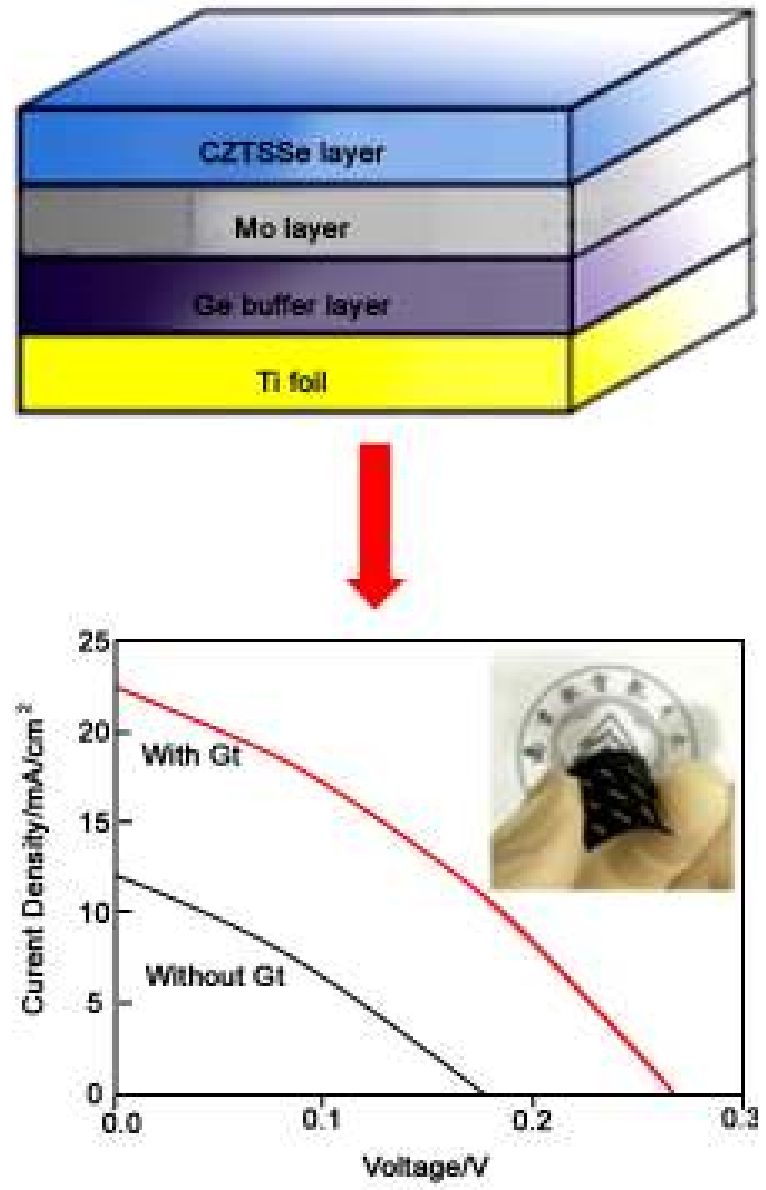

Fig. 7. CZTSSe solar cells (Li et al., 2017).

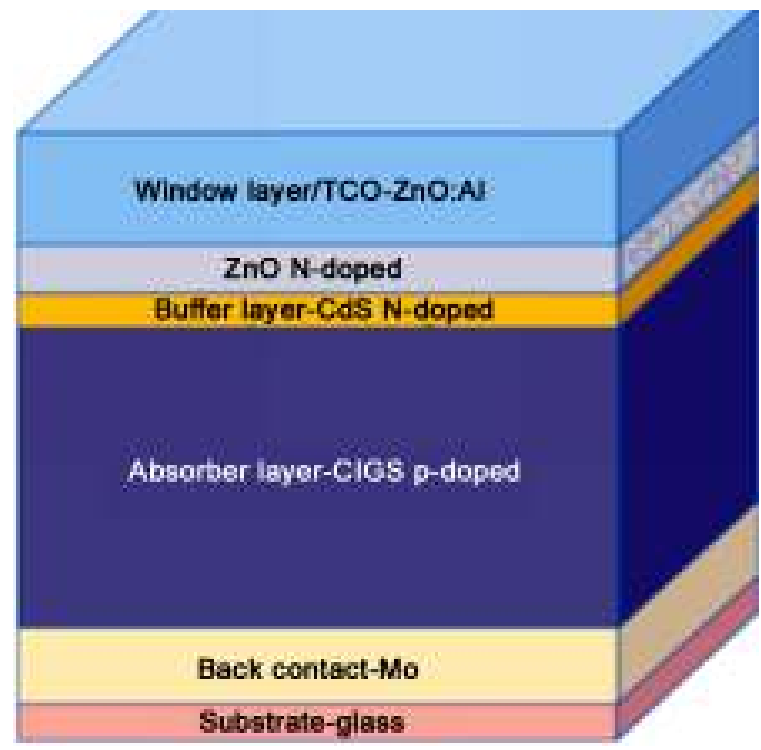

Fig. 8. Basic structure of CIGS (Parisi et al., 2015). 
It plays a significant role on the reduction of yield costs that is utilizing the axial motion about the construction of the CIGS films deposit. (Kurosawa et al., 2018; Reinhard et al., 2012).

Polyimide film CIGS based solar cells. Polyimide film CIGS based on solar cells is appeared to be unmanageable in the recent work to arrive at the operating stages on the elastic substratum that represents the glass preservation. The recent work of elastic polyimide demonstrates the decrease of gap efficiency. Various materials on a polyimide film that manifests the largest cell efficiency approximately $18.7 \%$ that utilized the elastic substratum similar to metals/plastics. Improvement in the efficiencies of the elastic solar cells have been achieved. This engineering technology is the conversion from the lab to the industrial generation and fabrication withstands of CIGS modules that is fundamental of CIGS deposition (Redinger et al., 2011).

Challenges in solar technology. Researchers are working on the solar cell technology i.e. on the smaller scale and the substance that constructs the highly efficient devices that have minute results but their functions are not stable or its functioning is too difficult to handle because major task is its stability. Our new research leads to new materials that are stable, efficient and affordable for the low price. Researchers are working on the limited levels whereas work on the power conversion demonstrates on the higher level because of its functioning polymer solar cell. If we work on the larger level than its processing will be problematic and science becomes the curiosity for the mankind (Krebs, 2009). Scragg et al. worked on electro deposition method for the manufacturing of the CZTS due to resolving of $\mathrm{CuCl} \mathrm{ZnCl} \mathrm{SnCl}$ individually with in $\mathrm{NaOH}$ and sorbitol. Electrochemical deposition that is like a coating method is used to differentiate cations in the aqueous solvent after 40 years of struggle. This method is used to manufacture with the efficiency of $6.03 \%$ (Ravindiran and Praveenkumar, 2018; Krebs, 2009; Li et al., 2006).

\section{Conclusion}

Power transfer efficiency of solar cells is enhanced by the utilization of copper zinc tin sulphide (CZTS) that is the best choice. This review is based on copper zinc tin sulphide (CZTS) and its various methods. To enhance the efficiency and stability it is the best alternate that is fundamental of many solar cells like cadmium (Cd) doping that is accomplished to improve the efficiency of copper zinc tin sulphide (CZTS). Ternary organic solar cell contains the researcher interest for the simplicity. Research workers worked on the effects of the nanofluids on aerodynamic. A thin film solar of cells have greater coefficient of absorption because of its high functioning and band gap value range in between 1.5 and $1.0 \mathrm{eV}$. The semiconductor photocatalytic water and air purification are the fundamental processes for the hydrogen generation process. Nano fluids are explored for the solar cells. Different kinds of solar cells are discovered with the passage of time and this review covers the shift from silicon solar cells to copper zinc tin sulphide (CZTS) and their efficiency is increased with the passage of time with different doping of materials. Nano fluids are bio compatibles and environment friendly that has been tested and their output are going to helpful in future applications. Future of solar cells and its efficiency will seem to have been maximized.

Conflict of Interest. The authors declare no conflict of interest.

\section{References}

Aberle, A.G. 2001. Overview on SiN surface passivation of crystalline silicon solar cells. Solar Energy Materials and Solar Cells, 65: 239-248.

Aberle, A.G. 2000. Surface passivation of crystalline silicon solar cells: a review. Progress in Photovoltaics: Research and Applications, 8: 473-487.

Ahlswede, E., Hanisch, J., Powalla, M. 2007. Comparative study of the influence of $\mathrm{LiF}, \mathrm{NaF}$, and $\mathrm{KF}$ on the performance of polymer bulk heterojunction solar cells. Applied Physics Letters, 90: 163504.

Akimov, Y.A., Ostrikov, K., Li, E. 2009. Surface plasmon enhancement of optical absorption in thin film silicon solar cells. Plasmonics, 4: 107-113.

Ansari, M.I.H., Qurashi, A., Nazeeruddin, M.K. 2018. Frontiers, opportunities, and challenges in perovskite solar cells: A critical review. Journal of PhotoChemistry and Photobiology C: Photochemistry Reviews, 35: 1-24.

Christians, J.A., Manser, J.S., Kamat, P.V. 2015. Best practices in perovskite solar cell efficiency measurements. Avoiding the error of making bad cells look good: ACS Publications, USA. http://doi.org/ 10.1021/acs.jpclett.5b00289

Deckman, H., Wronski, C., Witzke, H., Yablonovitch, E. 1983. Optically enhanced amorphous silicon solar cells. Applied Physics Letters, 42: 968-970. 
Dennler, G., Lungenschmied, C., Neugebauer, H., Sariciftci, N., Labouret, A. 2005. Flexible, conjugated polymer-fullerene-based bulk-heterojunction solar cells: Basics, encapsulation, and integration. Journal of Materials Research, 20: 3224-3233.

Dennler, G., Sariciftci, N.S. 2005. Flexible conjugated polymer-based plastic solar cells: From basics to applications. Proceedings of the IEEE, 93: 14291439.

Fu, H., Wang, Z., Sun, Y. 2018. Advances in nonfullerene acceptor based ternary organic solar cells. Solar RRL, 2: 1700158.

Fujishima, A., Honda, K. 1972. Electrochemical Photolysis of water at a semiconductor electrode. Nature, 238: 37-38.

Gordillo-Vazquez, F.J., Herrero, V.J., Tanarro, I. 2007. From carbon nanostructures to new photoluminescence sources: An overview of new perspectives and emerging applications of low-pressure PECVD. Chemical Vapor Deposition, 13: 267-279.

Green, M.A., Emery, K., Hishikawa, Y., Warta, W. 2011. Solar cell efficiency tables (version 37). Progress in Photovoltaics: Research and Applications, 19: 84-92.

Green, M.A. 2009. The path to $25 \%$ silicon solar cell efficiency: history of silicon cell evolution. Progress in Photovoltaics: Research and Applications, 17: 183-189.

Hjerrild, N.E., Mesgari, S., Crisostomo, F., Scott, J.A., Amal, R., Taylor, R.A. 2016. Hybrid PV/T enhancement using selectively absorbing $\mathrm{Ag}-\mathrm{SiO}_{2} /$ carbon nanofluids. Solar Energy Materials and Solar Cells, 147: 281-287.

Hu, L., Chen, G. 2007. Analysis of optical absorption in silicon nanowire arrays for photovoltaic applications. Nano Letters, 7: 3249-3252.

Jiang, K., Zhang, G., Yang, G., Zhang, J., Li, Z., Ma, T., Hu, H., Ma, W., Ade, H., Yan, H. 2018. Multiple cases of efficient nonfullerene ternary organic solar cells enabled by an effective morphology control method. Advanced Energy Materials, 8: 1701370.

Katagiri, H., Sasaguchi, N., Hando, S., Hoshino, S., Ohashi, J., Yokota, T. 1997. Preparation and evaluation of $\mathrm{CU}_{2} \mathrm{ZnSnS}_{4}$ thin films by sulfurization of E $\cdot$ B evaporated precursors. Solar Energy Materials and Solar Cells, 49: 407-414.

Kondo, Y., Yoshikawa, H., Awaga, K., Murayama, M., Mori, T., Sunada, K., Bandow, S., Iijima, S. 2008. Preparation, photocatalytic activities, and dyesensitized solar-cell performance of submicron- scale $\mathrm{TiO}_{2}$ hollow spheres. Langmuir, 24: 547-550.

Krebs, F.C. 2009. Fabrication and processing of polymer solar cells: a review of printing and coating techniques. Solar Energy Materials and Solar Cells, 93: 394-412.

Kurosawa, T., Gu, X., Gu, K.L., Zhou, Y., Yan, H., Wang, C., Wang, G.N., Toney, M.F., Bao, Z. 2018. Understanding the impact of oligomeric polystyrene side chain arrangement on the all-polymer solar cell performance. Advanced Energy Materials, 8: 1701552.

Kurokawa, Y., Tomita, S., Miyajima, S., Yamada, A., Konagai, M. 2007. Photoluminescence from silicon quantum dots in $\mathrm{Si}$ quantum dots/amorphous $\mathrm{SiC}$ superlattice. Japanese Journal of Applied Physics, 46: L833.

Lenert, A., Bierman, D.M., Nam, Y., Chan, W.R., Celanovic, I., Soljacic, M., Wang, E.N. 2014. A nanophotonic solar thermophotovoltaic device. Nature Nanotechnology, 9: 126.

Li, B., Wang, L., Kang, B., Wang, P., Qiu, Y. 2006. Review of recent progress in solid-state dyesensitized solar cells. Solar Energy Materials and Solar Cells, 90: 549-573.

Li, J., Shen, H., Shang, H., Li, Y., Wu, W. 2017. Performance improvement of flexible CZTSSe thin film solar cell by adding a Ge buffer layer. Materials Letters, 190: 188-190.

Liao, Y., Yuan, B., Zhang, D., Wang, X., Li, Y., Wen, Q., Zhang, H., Zhong, Z. 2018. A facile method for loading $\mathrm{CeO}_{2}$ nanoparticles on anodic $\mathrm{TiO}_{2}$ nanotube arrays. Nanoscale Research Letters, 13: 89.

Liu, J., Cao, G., Yang, Z., Wang, D., Dubois, D., Zhou, X., Graff, G.L., Pederson, L.R., Zhang, J.-G. 2008. Oriented nanostructures for energy conversion and storage. Chem Sus Chem, 1: 676-697.

Lungenschmied, C., Dennler, G., Neugebauer, H., Sariciftci, S.N., Glatthaar, M., Meyer, T., Mcyer, A. 2007. Flexible, long-lived, large-area, organic solar cells. Solar Energy Materials and Solar Cells, 91: 379-384.

Mahian, O., Kianifar, A., Kalogirou, S.A., Pop, I., Wongwises, S. 2013. A review of the applications of nanofluids in solar energy. International Journal of Heat and Mass Transfer, 57: 582-594.

Mekhilef, S., Saidur, R., Safari, A. 2011. A review on solar energy use in industries. Renewable and Sustainable Energy Reviews, 15: 1777-1790.

Ng, C., Lim, H., Hayase, S., Zainal, Z., Huang, N. 2018. 
Photovoltaic performances of mono and mixedhalide structures for perovskite solar cell: A review. Renewable and Sustainable Energy Reviews, 90: 248-274.

Ni, M., Leung, M.K., Leung, D.Y., Sumathy, K. 2007. A review and recent developments in photocatalytic water-splitting using $\mathrm{TiO}_{2}$ for hydrogen production. Renewable and Sustainable Energy Reviews, 11: 401-425.

Ostrikov, K., Xu, S., Huang, S., Levchenko, I. 2008. Nanoscale surface and interface engineering: Why plasma-aided. Surface and Coatings Technology, 202: 5314-5318.

Parisi, A., Pernice, R., Rocca, V., Curcio, L., Stivala, S., Cino, A.C., Cipriani, G., Dio, V.D., Galluzzo, G.R., Miceli, R., Busacca, A.C. 2015. Graded carrier concentration absorber profile for high efficiency CIGS solar cells. International Journal of Photoenergy, 2015: 9.

Pysch, D., Mette, A., Glunz, S.W. 2007. A review and comparison of different methods to determine the series resistance of solar cells. Solar Energy Materials and Solar Cells, 91: 1698-1706.

Rajeshwar, K., Osugi, M.E., Chanmanee, W., Chenthamarakshan, C.R., Zanoni, M.V.B., Kajitvichyanukul, P., Krishnan-Ayer, R. 2008. Heterogeneous photocatalytic treatment of organic dyes in air and aqueous media. Journal of Photochemistry and Photobiology C: Photochemistry Reviews, 9: 171-192.

Rand, B.P., Burk, D.P., Forrest, S.R. 2007a. Offset energies at organic semiconductor heterojunctions and their influence on the open-circuit voltage of thin-film solar cells. Physical Review B, 75: 115327.

Rand, B.P., Genoe, J., Heremans, P., Poortmans, J. 2007b. Solar cells utilizing small molecular weight organic semiconductors. Progress in Photovoltaics: Research and Applications, 15: 659-676.

Ravindiran, M., Praveenkumar, C. 2018. Status review and the future prospects of CZTS based solar cell-A novel approach on the device structure and material modeling for CZTS based photovoltaic device. Renewable and Sustainable Energy Reviews, 94: 317-329.

Redinger, A., Berg, D.M., Dale, P.J., Valle, N., Siebentritt, S. 2011. Route towards high efficiency single phase $\mathrm{Cu}_{2} \mathrm{ZnSn}(\mathrm{S}, \mathrm{Se})_{4}$ thin film solar cells: Model experiments and literature review, IEEE Journal of Photovoltaics, 2: 200-206.

Reinhard, P., Chirila, A., Blosch, P., Pianezzi, F.,
Nishiwaki, S., Buechelers, S., Tiwari, A.N. 2013. Review of progress toward $20 \%$ efficiency flexible CIGS solar cells and manufacturing issues of solar modules, IEEE Journal of Photovoltaics, 3: 572580.

Richards, B. 2004. Comparison of $\mathrm{TiO}_{2}$ and other dielectric coatings for buried-contact solar cells: a review. Progress in Photovoltaics: Research and Applications, 12: 253-281.

Saha, U., Alam, M.K. 2017. Proposition and computational analysis of a kesterite/kesterite tandem solar cell with enhanced efficiency. RSC Advances, 7: 4806-4814.

Sakthivel, T., Ashok Kumar, K., Ramanathan, R., Senthilselvan, J., Jagannathan, K. 2017. Silver doped $\mathrm{TiO}_{2}$ nano crystallites for dye-sensitized solar cell (DSSC) applications. Materials Research Express, 4: 126310.

Sharma, S., Jain, K.K., Sharma, A. 2015. Solar cells: in research and applications - a review. Materials Sciences and Applications, 6: 1145.

Siegel, A.C., Phillips, S.T., Dickey, M.D., Lu, N., Suo, Z., Whitesides, G.M. 2010. Foldable printed circuit boards on paper substrates. Advanced Functional Materials, 20: 28-35.

Tanabe, K. 2009. A review of ultrahigh efficiency III-V semiconductor compound solar cells: multijunction tandem, lower dimensional, photonic up/down conversion and plasmonic nanometallic structures. Energies, 2: 504-530.

Temple, T., Mahanama, G., Reehal, H., Bagnall, D. 2009. Influence of localized surface plasmon excitation in silver nanoparticles on the performance of silicon solar cells. Solar Energy Materials and Solar Cells, 93: 1978-1985.

Thomas, S., Deepak, T., Anjusree, G., Arun, T., Nair, S.V., Nair, A.S. 2014. A review on counter electrode materials in dye-sensitized solar cells. Journal of Materials Chemistry A, 2: 4474-4490.

Upama, M.B., Elumalai, N.K., Mahmud, M.A., Wright, M., Wang, D., Xu, C., Uddin, A. 2018. Effect of annealing dependent blend morphology and dielectric properties on the performance and stability of non-fullerene organic solar cells. Solar Energy Materials and Solar Cells, 176: 109-118.

Venkatraman, V., Raju, R., Oikonomopoulos, S.P., Alsberg, B.K. 2018. The dye-sensitized solar cell database. Journal of Cheminformatics, 10: 18.

Wu, F., Hu, X., Fan, J., Liu, E., Sun, T., Kang, L., Hou, W., Zhu, C., Liu, H. 2013. Photocatalytic activity 
of $\mathrm{Ag} / \mathrm{TiO}_{2}$ nanotube arrays enhanced by surface plasmon resonance and application in hydrogen evolution by water splitting. Plasmonics, 8: 501508.

Wu, X., Dhere, R., Albin, D., Gessert, T., DeHart, C., Keane, J., Duda, A., Coutts, T., Asher, S., Levi, D., Moutinho, H., Yan, Y., Moriarty, T., Johnston, S., Emery, K., Sheldon, P. 2001. High-efficiency $\mathrm{CTO} / \mathrm{ZTO} / \mathrm{CdS} / \mathrm{CdTe}$ polycrystalline thin-film solar cells. Paper presented at the NCPV Program Rreview Meeting.
Yang, J., Banerjee, A., Guha, S. 1997. Triple-junction amorphous silicon alloy solar cell with $14.6 \%$ initial and $13.0 \%$ stable conversion efficiencies. Applied Physics Letters, 70: 2975-2977.

Zekry, A.E.H. 2004. The Evaluation of Solar Cells Modules on The Long-Term Using DAS. M.Sc. Thesis, Ain Shams University, Egypt.

Zhai, H., Alexandrova, A.N. 2017. Fluxionality of Catalytic Clusters: When it Matters and How to Address it, ACS Publications, USA. doi.org/ 10.1021/acscatal.6b03243 